\title{
Influencing Health Beliefs and Sedentary Behaviours in Working Adults: A Video-Based Intervention Study
}

\author{
Melissa Peachey, Julie Richardson*, Vanina Dal Bello-Haas, Ada Tang \\ School of Rehabilitation Science, McMaster University, Hamilton, L8S 1C7, Canada \\ *Corresponding author: jrichard@mcmaster.ca
}

Received November 10, 2018; Revised January 07, 2019; Accepted January 17, 2019

\begin{abstract}
Adults working in academic occupations are at risk for exposure to sedentary behaviours. The aim of this study was to determine the influence of an educational video on viewer's health beliefs and sedentary behaviours. Data was collected between March and April 2017 from healthy adults employed in an academic institution in Ontario, Canada ( $\mathrm{n}=71$; age $=40.0 \pm 12.1$ y) using a single-group, pre-post design. Evidence-based strategies to reduce sedentary behaviour at home and at work were summarized and presented as cues to action in a 5-minute video. Self-reported physical activity, sedentary behaviours, health beliefs, and readiness to change were measured using the International Physical Activity Questionnaire, Sedentary behaviour Health Belief Questionnaire, and Readiness Ruler, respectively, one week before (T1), immediately after (T2), and one week after watching the video (T3). Occupational and leisure-time sitting time was assessed daily via participant log. Participants reduced weekday and weekend sitting time by-35.9 minutes/day $(\mathrm{p}=0.03)$ and-21.1 minutes/day $(\mathrm{p}=0.01)$, respectively. Readiness to change increased between T2 and T3 $(\mathrm{p}=0.004)$. Perceived severity of $(\mathrm{p}=0.03)$ and susceptibility to $(\mathrm{p}=0.01)$ the health risks associated with sedentary behaviour increased from T1 to T2. Perceived benefit scores $\left(r_{s}=-0.25, p=0.04\right)$ at $\mathrm{T} 2$ were inversely associated with reductions in sitting time from T2 to T3. It is possible that exposure to the video influenced several health benefits constructs and reduced daily sitting time in healthy adults working in academic occupations.
\end{abstract}

Keywords: adult, sedentary lifestyle, occupational group, health education, exercise

Cite This Article: Melissa Peachey, Julie Richardson, Vanina Dal Bello-Haas, and Ada Tang, "Influencing Health Beliefs and sedentary Behaviours in Working Adults: A Video-Based Intervention Study." Journal of Physical Activity Research, vol. 4, no. 1 (2019): 34-40. doi: 10.12691/jpar-4-1-3.

\section{Introduction}

Despite growing evidence linking sedentary behaviour with negative health outcomes, $85 \%$ of Canadians are not meeting physical activity recommendations and are instead spending 10 of their daily waking hours in a sedentary state. [1] sedentary behaviour, defined as any waking activity with an energy expenditure of $\leq 1.5$ metabolic energy equivalents, [2] is a major public health problem. [1] Greater daily sitting time is associated with increased risk of mortality from all causes. [3]

Interventions to reduce adult sedentary behaviour have been successful and evidence from two recent systematic reviews $[4,5]$ indicate that sedentary behaviour interventions can reduce daily sitting time in the range of 42 [4] to 91 [5] minutes per day. Adults working in academic occupations are a logical target for sedentary behaviour interventions since professors, graduate students, and research support staff spend most of their workday in a seated position. [6] of 5000 academic staff surveyed in the UK, 66\% reported working more than 45 hours per week, and $24 \%$ percent reported working more than 55 hours per week. [6] Nearly $45 \%$ of the survey sample reported completing more than a fifth of their workload in the evenings and on weekends. [6] Given that university faculty members are sedentary nearly 8 hours of every day, [6] professional staff that work at higher education institutions are sedentary for more than 11 hours every day, [7] and that more than half of Canadian university students are not meeting physical activity guidelines, [8] sedentary behaviour interventions in these populations is warranted.

The purpose of this study was to examine the effectiveness of using a video to influence health beliefs to reduce sedentary behaviour by providing targeted, evidence-based strategies to reduce sitting time at home and at work for healthy adults working in academic occupations.

\section{Materials and Methods}

\subsection{Study Population and Study Design}

Participants were recruited via departmental email and included if they met the following criteria: aged 18-65 
years and were a student, full-time or sessional faculty member, or research support staff within the School of Rehabilitation Science, McMaster University. Participants were excluded if they had any known musculoskeletal conditions that would prevent them from being less sedentary. Informed consent was obtained from all participants prior to participation in this study. The Hamilton Integrated Research Ethics Board approved the experimental protocol, recruitment materials, study questionnaires, and intervention content (2017-1854-GRA).

Participants completed all assessments between March and April 2017. Data were analyzed in May 2017. This study employed a single-group, pre-post design to evaluate sitting time of participants 1-week before, immediately after watching an educational video, and 1-week later.

\subsection{Intervention}

The video was 5 minutes in length and provided participants with a comprehensive overview of the nature, scope, and impact of sedentary behaviour as a public health problem. The video addressed working-age adults' perceived susceptibility to the health risks associated with sedentary behaviour and the severity of those health consequences. The evidence for strategies to reduce sedentary behaviour in the home and workplace environments was systematically reviewed, [9] summarized, and presented as cues to action in the video. The video was uploaded to Vimeo and sent to participants using the following link: https://vimeo.com/210495060.

\subsection{Outcome Measures}

\subsubsection{International Physical Activity Questionnaire (IPAQ)}

The primary outcome was the proportion of participants who reduced their sitting time by $30 \mathrm{~min} /$ day as measured by the Short-form IPAQ. [10] The IPAQ demonstrates excellent test-retest reliability $(\mathrm{ICC}=0.76)$, and fair criterion validity $(\mathrm{r}=0.30)$ when compared against accelerometry in samples of middle-aged, well-educated, working adults. [10] Participants were asked to fill out electronic versions of the short-form IPAQ at baseline (T1), immediately after watching the video (T2), and one week later (T3).

\subsubsection{Sedentary Behaviour Health Belief Questionnaire (SB-HBQ)}

We assembled a SB-HBQ based on an extended version of the Health Belief Model. [11] Including four additional constructs improved the predictive capability of the original model by $78 \%$. [11] These additional constructs include: self-identity, consideration of future consequences, concern for appearance, and perceived importance. [11] For the present study, subscales were developed for each of the nine constructs outlined in Orji et al.'s (2012) extended Health Belief Model. Participants were asked to rate statements on a 5-point Likert Scale from $1=$ strongly disagree to $5=$ strongly agree. Statements were modified from previously validated questionnaires. [12-17] further information about the adapted SB-HBQ is available upon request.

\subsection{Readiness Ruler}

An electronic version of a Readiness Ruler was developed which required participants to indicate their readiness to change on a 10 -point scale, where $1=$ Not prepared to change and $10=$ Already changing. The Readiness Ruler was sent to participants at baseline, immediately after watching the video and one week later.

\subsection{Log}

For one week starting at baseline, participants received a daily email reminder to complete and submit an electronic log of the amount of time spent being sedentary in the previous day by clicking on the link provided. The log prompted individuals to record the amount of time they spent sitting in the following activities: watching television, working, eating meals, using their computer at home, travelling, participating in hobbies, and socializing with friends or family. At the end of the first week, the educational video was sent to participants. For one week following receipt of the video, participants received a daily email reminder to fill out and submit an electronic log of the time spent in sedentary behaviour in the previous day by clicking on the link provided.

\subsection{Video Evaluation}

Participants were asked to fill out an evaluation survey immediately after watching the video. The survey used a 5-point Likert scale for participants to rate the content (1=poor, 5=excellent), design (1=totally unacceptable, $5=$ extremely acceptable), and impact of the video $(1=$ not at all influential, 5=extremely influential).

\subsection{Sample Size}

Sample size calculation was performed using Stata software, version 13 (StataCorp, College Station, TX, USA). Significance level was set at 0.05 , power at 0.8 , and a minimum detectable difference of 30 minutes of sitting per day (as measured by the IPAQ at baseline and follow-up) was used as the alternative hypothesis, with a standard deviation of 1.25 hours of sitting per day based on a previous intervention in a similar population. [18] The sample size calculated was 52 participants. To account for a potential $20 \%$ dropout rate, the investigators aimed to recruit 63 participants.

\subsection{Statistical Analysis}

Statistical analysis was conducted using Stata software, version 13 (StataCorp, College Station, TX, USA). Baseline characteristics are presented as means and standard deviations for data that was normally distributed and medians and interquartile range for data not normally distributed. Data was collected and stored on secure servers at the Institute of Applied Health Sciences at McMaster University. 


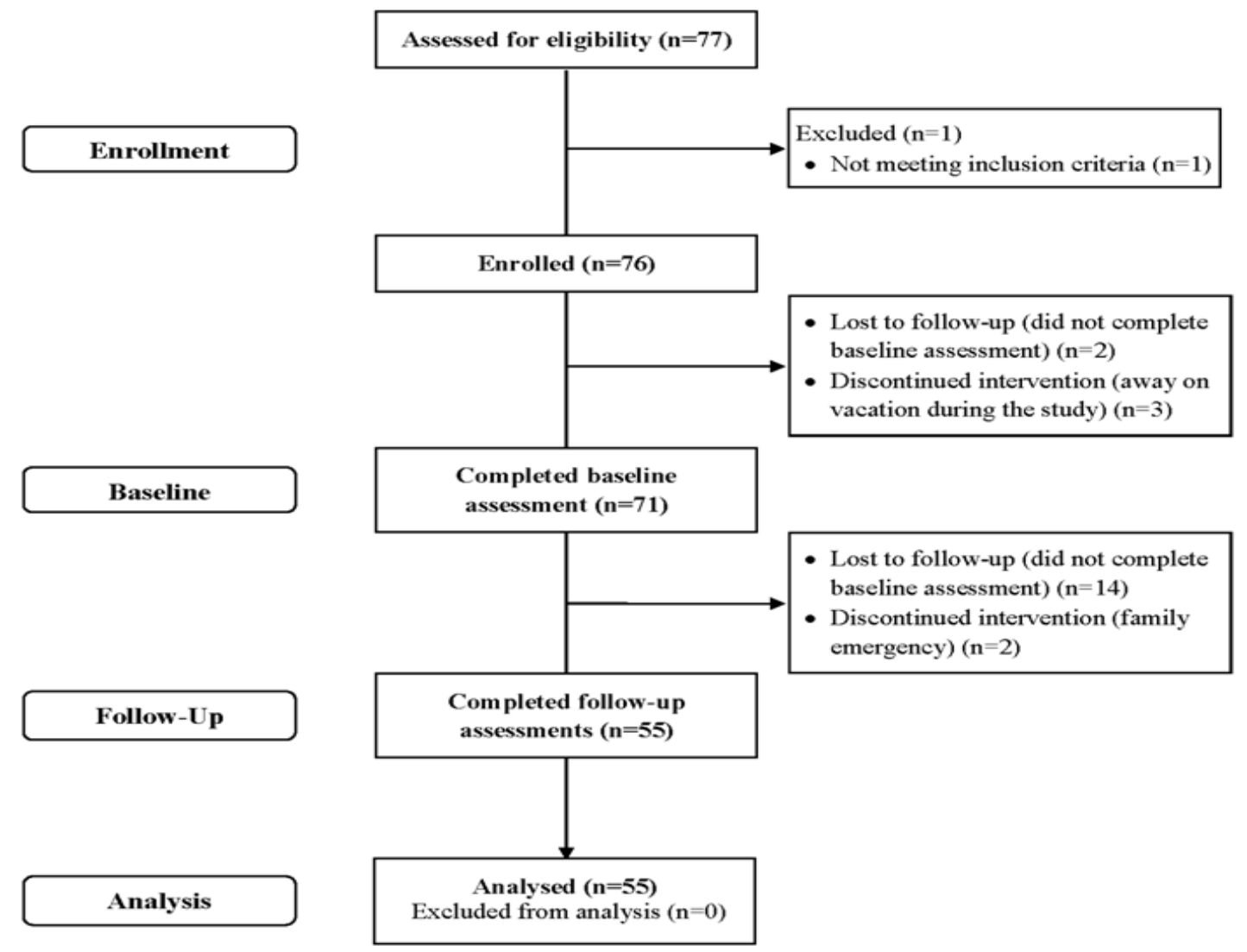

Figure 1. CONSORT Flow Diagram

To determine the respective effects of the intervention on daily sitting time and health beliefs, a paired sample t-test was used, or Wilcoxon signed-rank test when appropriate, to calculate the differences in sitting time and health belief subscale scores between $\mathrm{T} 1$ and $\mathrm{T} 2$ as well as between T2 and T3. Acceptability of the video intervention and suggestions for improvement were evaluated based on responses to the video evaluation survey.

\section{Results}

A total of 77 participants were assessed for eligibility, of which one person was excluded due to a pre-existing musculoskeletal condition (Figure 1). Of the 76 eligible participants, 71 completed the baseline assessment. Three participants did not complete the baseline assessments as they were on vacation. Assessments at all three time-points including baseline, post-intervention, and one-week follow-up, were completed by $51(72 \%)$ participants. In total, $19(27 \%)$ participants were lost to follow-up and 2 (3\%) participants dropped out of the study. Overall, participants were mostly female, middle-aged, and reported a normal to overweight body mass index. Baseline group characteristics are presented in Table 1.

Table 1. Demographic characteristics of study participants

\begin{tabular}{|l|l|}
\hline & All participants $(\mathrm{n}=71)$ \\
\hline Age, Mean (SD) & 40.0 years $(12.1)$ \\
\hline Female, $\mathrm{n}(\%)$ & $60(88.2)$ \\
\hline Occupation & \\
Student, n (\%) & $31(45.6)$ \\
Faculty, n (\%) & $20(29.4)$ \\
Research support staff, n (\%) & $17(25)$ \\
\hline Body Mass Index, Mean (SD) & $26.3(6.4)$ \\
\hline
\end{tabular}

\subsection{Missing Data}

Missing data were imputed by carrying the last observation forward. [19] Statistical analyses were performed two ways: with and without the imputed data. Results using complete case analysis indicated that increases in weekday sitting time from $\mathrm{T} 1$ to $\mathrm{T} 2$ were not significant $(\mathrm{p}=0.08)$. Details about the complete case analysis are available on request. Results for analyses with imputed data are shown below.

\subsection{International Physical Activity Questionnaire (IPAQ)}

Table 2 illustrates mean changes in IPAQ scores from baseline (T1) to post-intervention (T2) and from post-intervention (T2) to follow-up (T3). Weekday sitting time increased from T1 to T2 (460.1 minutes/day, 482.5 minutes/day, $\mathrm{p}=0.04)$. There was a decrease in sedentary behaviour between T2 and T3 for both weekday (482.5 minutes/day, 446.6 minutes/day, $\mathrm{p}=0.03$ ) and weekend sitting time (341.4 minutes/day, 320.3 minutes/day, $\mathrm{p}=0.01)$. There were no differences observed in sitting time between $\mathrm{T} 1$ and $\mathrm{T} 2$. The number of days participants walked at least 10 minutes per day increased from $\mathrm{T} 1$ to $\mathrm{T} 2(\mathrm{p}=0.001)$.

\subsection{Health Beliefs}

Changes in health beliefs are summarized in Table 3. Both perceived susceptibility $(13,14.5, \mathrm{p}=0.01)$ and perceived severity $(21.5,23, \mathrm{p}=0.03)$ increased from $\mathrm{T} 1$ to T2. No intervention effects were observed for any of the other subscales between $\mathrm{T} 1$ and $\mathrm{T} 2$. A decrease in 
consideration of future consequences subscale scores was observed between post-intervention (T2) and follow-up (T3) $(36,35, p=0.01)$. No intervention effects were observed for any other subscale between T2 and T3.

\subsection{Perceived Benefits, Barriers, and Cues to Action}

Participants were instructed to check all appropriate responses based on what they perceived to be benefits, barriers, and cues to action to changing their sedentary behaviour from a list of 11 potential benefits, 12 barriers, and 11 cues. The top three benefits that participants reported included 'improve my health' $(94.0 \%)$, 'make me more active' (83.1\%), and 'improve my fitness' $(80.6 \%)$, The top three barriers reported were 'the nature of my job'
(80.6\%), 'job workload' (67.2\%), and 'not having a standing desk' (58.2\%). Cues to action reported most frequently included 'being prompted/reminded to break up prolonged bouts of sitting' (76.1\%), 'having a standing desk' (68.7\%), and 'having walking meetings' (67.2\%).

\subsection{Readiness to Change}

Readiness to Change scores are presented in Table 4. Changes between T1 and T2 were not observed, however Readiness to Change increased from T2 to T3 (6, 7, $\mathrm{p}=0.04$ ). Readiness to Change scores at $\mathrm{T} 1$ were not associated with changes in sitting time from $\mathrm{T} 2$ to $\mathrm{T} 3$. Readiness to Change scores at $\mathrm{T} 2$ were inversely associated with changes in sitting time from $\mathrm{T} 2$ to $\mathrm{T} 3$ $\left(\mathrm{r}_{\mathrm{s}}=-0.26, \mathrm{p}=0.03\right)$.

Table 2. International Physical Activity Questionnaire; Mean (SD)

\begin{tabular}{|c|c|c|c|c|c|c|c|}
\hline Time & $\begin{array}{c}\mathrm{T} 1 \\
\mathrm{n}=71\end{array}$ & $\begin{array}{c}\mathrm{T} 2 \\
\mathrm{n}=71\end{array}$ & $\begin{array}{c}\mathrm{T} 3 \\
\mathrm{n}=71\end{array}$ & $\begin{array}{c}\text { Mean change } \\
\text { (T2-T1) }\end{array}$ & p-value & $\begin{array}{c}\text { Mean change } \\
\text { (T3-T2) }\end{array}$ & p-value \\
\hline Weekday sitting time (min) & $\begin{array}{c}460.1 \\
(148.8) \\
\end{array}$ & $\begin{array}{c}482.5 \\
(153.0) \\
\end{array}$ & $\begin{array}{c}446.6 \\
(147.8) \\
\end{array}$ & $\begin{array}{c}22.40 \\
(106.3) \\
\end{array}$ & 0.04 & $\begin{array}{l}-35.92 \\
(132.4) \\
\end{array}$ & 0.03 \\
\hline Weekend sitting time (min) & $\begin{array}{c}326.2 \\
(138.3) \\
\end{array}$ & $\begin{array}{c}341.4 \\
(138.6) \\
\end{array}$ & $\begin{array}{c}320.3 \\
(150.5) \\
\end{array}$ & $\begin{array}{c}15.21 \\
(124.6) \\
\end{array}$ & 0.64 & $\begin{array}{l}-21.13 \\
(154.3) \\
\end{array}$ & 0.01 \\
\hline Walking (days/week) & $\begin{array}{c}4.8 \\
(2.2)\end{array}$ & $\begin{array}{c}5.1 \\
(2.1)\end{array}$ & $\begin{array}{l}5.25 \\
(2.04)\end{array}$ & $\begin{array}{c}0.3 \\
(1.6)\end{array}$ & 0.001 & $\begin{array}{c}0.141 \\
(0.975)\end{array}$ & 0.37 \\
\hline Walking (min/day) & $\begin{array}{c}49.1 \\
(53.9)\end{array}$ & $\begin{array}{c}50.6 \\
(56.9)\end{array}$ & $\begin{array}{c}51.5 \\
(50.6)\end{array}$ & $\begin{array}{c}1.48 \\
(29.2)\end{array}$ & 0.18 & $\begin{array}{c}0.88 \\
(43.35)\end{array}$ & 0.26 \\
\hline Moderate PA (days/week) & $\begin{array}{c}2.5 \\
(2.2)\end{array}$ & $\begin{array}{c}2.3 \\
(2.2)\end{array}$ & $\begin{array}{c}2.47 \\
(1.74)\end{array}$ & $\begin{array}{l}0.27 \\
(1.7)\end{array}$ & 0.53 & $\begin{array}{c}0.20 \\
(1.88)\end{array}$ & 0.38 \\
\hline Moderate PA (min/day) & $\begin{array}{c}55.6 \\
(60.2) \\
\end{array}$ & $\begin{array}{c}56.9 \\
(61.0) \\
\end{array}$ & $\begin{array}{c}62.4 \\
(59.5) \\
\end{array}$ & $\begin{array}{c}1.25 \\
(61.4) \\
\end{array}$ & 0.76 & $\begin{array}{c}5.46 \\
(57.1) \\
\end{array}$ & 0.57 \\
\hline Vigorous PA (days/week) & $\begin{array}{c}2.0 \\
(1.8)\end{array}$ & $\begin{array}{c}2.0 \\
(1.8)\end{array}$ & $\begin{array}{c}2.1 \\
(1.9)\end{array}$ & $\begin{array}{c}0.1 \\
(1.4)\end{array}$ & 0.82 & $\begin{array}{c}0.1 \\
(1.2)\end{array}$ & 0.78 \\
\hline Vigorous PA (min/day) & $\begin{array}{c}50.9 \\
(40.7)\end{array}$ & $\begin{array}{c}46.8 \\
(45.2)\end{array}$ & $\begin{array}{c}53.4 \\
(52.9)\end{array}$ & $\begin{array}{l}-3.48 \\
(35.7)\end{array}$ & 0.30 & $\begin{array}{c}6.57 \\
(43.6)\end{array}$ & 0.47 \\
\hline
\end{tabular}

Min: minutes; PA: physical activity.

Table 3. Sedentary Behaviour Health Belief Questionnaire, Subscale Scores; Median (IQR)

\begin{tabular}{|c|c|c|c|c|c|c|c|}
\hline $\begin{array}{l}\text { Subscale } \\
\text { (score range) }\end{array}$ & $\begin{array}{c}\mathrm{T} 1 \\
\mathrm{n}=71\end{array}$ & $\begin{array}{c}\mathrm{T} 2 \\
\mathrm{n}=71\end{array}$ & $\begin{array}{c}\mathrm{T} 3 \\
\mathrm{n}=71\end{array}$ & $\begin{array}{l}\text { Mean change } \\
(\mathrm{T} 2-\mathrm{T} 1)\end{array}$ & p-value & $\begin{array}{l}\text { Mean change } \\
\text { (T3-T2) }\end{array}$ & p-value \\
\hline $\begin{array}{l}\text { Perceived Susceptibility } \\
(5-25)\end{array}$ & $\begin{array}{c}13 \\
(11-16)\end{array}$ & $\begin{array}{c}14.5 \\
(11-16.5) \\
\end{array}$ & $\begin{array}{c}14 \\
(11-16.5) \\
\end{array}$ & $\begin{array}{c}0 \\
(0-2)\end{array}$ & 0.01 & $\begin{array}{c}0 \\
(0-1)\end{array}$ & 0.41 \\
\hline $\begin{array}{l}\text { Perceived Severity } \\
(5-25)\end{array}$ & $\begin{array}{c}21.5 \\
(20-24) \\
\end{array}$ & $\begin{array}{c}23 \\
(21-24) \\
\end{array}$ & $\begin{array}{c}2 \\
(20-24) \\
\end{array}$ & $\begin{array}{c}0 \\
(0-1) \\
\end{array}$ & 0.03 & $\begin{array}{c}0 \\
(-1)-0 \\
\end{array}$ & 0.11 \\
\hline $\begin{array}{l}\text { Perceived Benefits } \\
(4-20)\end{array}$ & $\begin{array}{c}16 \\
(15-18)\end{array}$ & $\begin{array}{c}16 \\
(15-18)\end{array}$ & $\begin{array}{c}16 \\
(15-19)\end{array}$ & $\begin{array}{c}0 \\
(-1)-1\end{array}$ & 0.45 & $\begin{array}{c}0 \\
(-0.5)-1\end{array}$ & 0.60 \\
\hline $\begin{array}{l}\text { Perceived Barriers } \\
(7-35)\end{array}$ & $\begin{array}{c}22.5 \\
(18-26)\end{array}$ & $\begin{array}{c}23 \\
(19.5-25.5) \\
\end{array}$ & $\begin{array}{c}24 \\
(20-26) \\
\end{array}$ & $\begin{array}{c}0 \\
(-1.5)-2 \\
\end{array}$ & 0.73 & $\begin{array}{c}0 \\
(-1)-2 \\
\end{array}$ & 0.23 \\
\hline $\begin{array}{l}\text { Self-efficacy } \\
(2-10)\end{array}$ & $\begin{array}{c}8 \\
(7-8)\end{array}$ & $\begin{array}{c}8 \\
(8-8)\end{array}$ & $\begin{array}{c}8 \\
(7.5-8)\end{array}$ & $\begin{array}{c}0 \\
(0-0)\end{array}$ & 0.93 & $\begin{array}{c}0 \\
(0-0)\end{array}$ & 0.27 \\
\hline $\begin{array}{l}\text { Concern for Appearance } \\
(4-20)\end{array}$ & $\begin{array}{c}16 \\
(14-16) \\
\end{array}$ & $\begin{array}{c}16 \\
(14-17) \\
\end{array}$ & $\begin{array}{c}16 \\
(14-17) \\
\end{array}$ & $\begin{array}{c}0 \\
(0-0) \\
\end{array}$ & 0.30 & $\begin{array}{c}0 \\
(0-0) \\
\end{array}$ & 0.52 \\
\hline $\begin{array}{l}\text { Future Consequences } \\
(12-60)\end{array}$ & $\begin{array}{c}36 \\
(33-38) \\
\end{array}$ & $\begin{array}{c}36 \\
(34-39) \\
\end{array}$ & $\begin{array}{c}35 \\
(33-38) \\
\end{array}$ & $\begin{array}{c}0 \\
(-1)-1 \\
\end{array}$ & 0.98 & $\begin{array}{c}0 \\
(-2)-0 \\
\end{array}$ & 0.005 \\
\hline $\begin{array}{l}\text { Self-identity } \\
(3-15)\end{array}$ & $\begin{array}{c}12 \\
(11-15)\end{array}$ & $\begin{array}{c}12 \\
(12-14)\end{array}$ & $\begin{array}{c}12 \\
(12-15)\end{array}$ & $\begin{array}{c}0 \\
(0-0)\end{array}$ & 0.96 & $\begin{array}{c}0 \\
(0-0)\end{array}$ & 0.54 \\
\hline $\begin{array}{l}\text { Perceived Importance } \\
(3-15)\end{array}$ & $\begin{array}{c}12 \\
(11-13)\end{array}$ & $\begin{array}{c}12 \\
(11-13)\end{array}$ & $\begin{array}{c}12 \\
(11-12)\end{array}$ & $\begin{array}{c}0 \\
(0-0)\end{array}$ & 0.89 & $\begin{array}{c}0 \\
(0-0)\end{array}$ & 0.40 \\
\hline
\end{tabular}

Table 4. Readiness Ruler; Median (IQR)

\begin{tabular}{|c|c|c|c|c|c|c|c|}
\hline & $\begin{array}{c}\mathrm{T} 1 \\
\mathrm{n}=71\end{array}$ & $\begin{array}{c}\mathrm{T} 2 \\
\mathrm{n}=71\end{array}$ & $\begin{array}{c}\mathrm{T} 3 \\
\mathrm{n}=71\end{array}$ & $\begin{array}{l}\text { Mean change } \\
\quad(\mathrm{T} 2-\mathrm{T} 1)\end{array}$ & p-value & $\begin{array}{l}\text { Mean change } \\
\quad(\mathrm{T} 3-\mathrm{T} 2)\end{array}$ & p-value \\
\hline $\begin{array}{l}\text { Readiness to Change } \\
(1-10)\end{array}$ & $\begin{array}{c}6 \\
(5-7)\end{array}$ & $\begin{array}{c}6 \\
(5-8)\end{array}$ & $\begin{array}{c}7 \\
(6-8)\end{array}$ & $0(-1)-1$ & 0.51 & $0(0-1)$ & 0.04 \\
\hline
\end{tabular}




\subsection{Log Data}

The greatest amount of domain-specific sitting time reported was for completing paperwork at work $(12.8 \mathrm{hrs} / \mathrm{wk} . \pm 7.7)$ and at home $(13.3 \mathrm{hrs} / \mathrm{wk} . \pm 8.2)$. Total sitting time on Mondays (-1.6hrs/day $\pm 3.0, \mathrm{p}<0.001)$, Wednesdays $(-0.9 \mathrm{hrs} /$ day $\pm 3.0, \mathrm{p}=0.02)$, and Thursdays $(-0.8 \mathrm{hrs} /$ day \pm 2.3 , $\mathrm{p}=0.01)$ significantly decreased. Sitting while completing paperwork at work $(-2.1 \pm 7.8, \mathrm{p}=0.002)$ and participating in hobbies $(-1 \pm 2.8, \mathrm{p}<0.001)$ significantly decreased.

\subsection{Health Belief Subscale Scores and Changes in Sitting Time}

No association was observed between any health belief subscale score at baseline (T1) and changes in sitting time between T2 and T3. Perceived benefits $\left(\mathrm{r}_{\mathrm{s}}=-0.25, \mathrm{p}=0.04\right)$ scores at $\mathrm{T} 2$ were inversely associated with changes in sitting time from $\mathrm{T} 2$ to $\mathrm{T} 3$. No other associations between health belief subscale scores and changes in sitting time were observed.

\subsection{Video Evaluation}

Over a third (37.7\%) of participants rated the video's content as 'excellent' (5), with a median rating of 4 . Median ratings for the video's design, graphics, and music were a 4. Median rating for overall impression of the video was a 4 with close to $32 \%$ of participants rating their impression as a $5 / 5$. When asked if they would recommend the video to a friend, $88.5 \%$ of participants said 'yes'. Suggestions for improvement included adding audio or voiceover $(n=7)$, increasing the speed of the video $(n=5)$, and shortening the overall length $(n=5)$.

\section{Discussion}

The purpose of this study was to determine whether exposure to evidence-based strategies for reducing sitting at home and at work via an educational video altered the health beliefs and reduced daily sitting time of healthy adults working in academic occupations. Following the intervention, participants reduced their weekday sitting by-35.9 minutes/day and weekend sitting by-21.2 minutes/day. Importantly, the reduction in weekday sitting (-35 minutes) observed between post-intervention (T2) and follow-up (T3) exceeded 30 minutes. Replacing 30 minutes of sedentary behaviour with light-intensity activity has been shown to lead to beneficial changes in clinical biomarkers (i.e. tri-glycerides, insulin levels, and Beta-cell function) [20] and thus exceeding this threshold could be considered an indication of intervention success. These findings are consistent with two recent systematic reviews and meta-analyses. [4,9] The first review (34 included studies) indicated sedentary behaviour-focused interventions were capable of reducing sitting time by-41 minutes/day, [9] while the second (38 included studies) reported an average reduction in sitting time of-30 minutes/day for sedentary behaviour-focused interventions. [4].

Accelerometer data from the 2003-2006 National Health and Nutrition Examination Survey (NHANES) indicates that for less-active individuals $(<5.8 \mathrm{hrs}$ total activity/day), replacing 1 hour of sedentary time with light or moderate-to-vigorous physical activity is associated with an $18-42 \%$ lower risk of mortality. [21] Though no changes were observed for moderate or vigorous physical activity in this study, the IPAQ does not ask participants about the amount of time they spend in light or incidental physical activity. Given the strong inverse association between sedentary behaviour and light physical activity, [22] it is likely that participants in this study displaced sitting time with standing and light ambulation. Changes in light physical activity are beneficially associated with decreased waist circumference and 2-hour plasma glucose levels [22,23] and are thus a desirable outcome for a sedentary behaviour intervention.

Consistent with data from the Canadian Health Measures Survey, sedentary behaviour logs confirmed participants sat nearly 10 hours on weekdays and 8 hours on weekend days. [24] Sitting during occupational tasks contributed the greatest amount of time to domain-specific sedentary behaviour. As expected, adults working in academic occupations reported high levels of sedentary behaviour. This is consistent with evidence from two systematic reviews reporting positive associations between educational attainment, socioeconomic status, and working in a professional role with occupational sitting time. $[25,26]$.

The aim of the video was to influence viewer's health beliefs and indeed, an increase was observed between $\mathrm{T} 1$ and T2 for perceived severity, and susceptibility subscale scores. However, no other changes in health belief subscale scores between T1 and T2 were observed. Overall, consideration of future consequences scores were lower at T3 than at T2 indicating that participants were less concerned with the future consequences of their sedentary behaviour by the end of the study. It is possible that the act of changing a negative health behaviour such as sedentary behaviour could make an individual feel less concerned about the future consequences of his or her actions by providing a sense of affirmative action towards their future health. More likely, as suggested in the literature, the value of short-term costs and benefits are more important determinants of preventive health behaviours than the value of long-term consequences. [27] Whether the consideration of immediate consequences is a more important determinant of sedentary behaviour in the adult population than consideration of future consequences is not yet known.

\subsection{Limitations}

The current study is not without limitations. First, the small, homogeneous sample of faculty members, graduate students, and research support staff at a single university is likely not representative of academic workers. Sedentary behaviour patterns vary for different occupations within an academic setting [7] and thus generalizability of our study results may be limited. It is possible that due to the education level and research focus on physical function and activity, graduate students and faculty members recruited from the School of Rehabilitation Science may have been aware of the health effects of sedentary behaviour and had already taken steps to reduce their 
sitting. Results from a focus group conducted in a similar demographic to the sample included in the present study indicated that middle-aged, female, full-time employees were aware that prolonged sitting was bad for health and that occupational sitting was the biggest contributor to daily sedentary behaviour. [28] For this reason, baseline IPAQ scores helped to capture participant's physical activity and sedentary behaviour status prior to participation in the study. Second, without a control group, the true effect of the intervention on sedentary behaviour cannot be isolated from outside factors. To account for any temporal changes in sedentary behaviour, each participant was asked to log his or her daily sitting time for one week prior to receiving the intervention. We were then able to make a meaningful comparison between a participant's usual sedentary behaviour at baseline and any changes to sedentary behaviour made one week after watching the educational video. Third, all measures were self-reported and are thus subject to recall bias as well as perception bias. Adapting previously validated scales into the SB-HBQ may have introduced measurement error, however we were not able to identify another measure of sedentary behaviour health beliefs. The measures of this study were chosen to maximize adherence and minimize participant burden. Participants were able to complete the questionnaires at their own convenience, in the privacy of their own home or place of work, and the survey completion was easy to assess. Fourth, our study was only two-weeks in duration, which represents a short window of observation into participants' usual pattern of sedentary behaviour and limits our ability to determine whether changes in sitting persisted longerterm. Finally, the intervention was delivered entirely online, making it difficult to ensure participants had watched the entire video, so we are unable to comment on the exposure or dose associated with the intervention. Treatment fidelity could have been compromised should participants have watched some, but not all, of the video.

\subsection{Strengths}

Despite these limitations, web-based interventions offer several advantages including increased: accessibility, data completion, and standardization, as well as reduced cost. [29] This study was designed to be low risk and low burden to appropriately meet the needs of a healthy, working-age adult population. The main strength of this study was that media was successfully used to convey an important, evidence-based, public health message that was well received by its audience. The feedback from participants was very positive overall. The video developed for this intervention has the potential to be scaled up for much larger audiences. It would not be difficult for an employer or organization to circulate the video to its employees or for a healthcare provider to share with his or her patients.

\section{Conclusion}

A brief, 5-minute educational video influenced health beliefs and reduced daily sitting time in a sample of healthy adults working in sedentary occupations. By the end of the two-week intervention, participants had reduced their total weekly sitting time by nearly 220 minutes.
Eighty-eight percent of participants would recommend the educational video to a friend, indicating the intervention was well received. This study is among the first to explore the relationship between health belief constructs and adult sedentary behaviour. Our findings do align with the limited literature on health beliefs and sedentary behaviour, though our results are limited by a lack of control group, use of some author-developed measures, a small sample size, and lack of long-term follow-up. There is a need to develop validated instruments for assessing health belief constructs specific to sedentary behaviour in the adult population. The extended Health Belief Model, as proposed by Orji et al. [11] has the potential to expand our understanding of the determinants of adult sedentary behaviour and how they might be influenced through intervention. Given the success of our brief video-based intervention, future testing with a more heterogeneous sample over a longer duration is warranted.

\section{Acknowledgements}

N/A.

\section{Statement of Competing Interests}

The authors have no competing interests.

\section{Abbreviations \\ International Physical Activity Questionnaire (IPAQ). Sedentary Behaviour Health Belief Questionnaire (SB-HBQ).}

\section{References}

[1] Bounajm, M.A., Dinh, T., Theriault, M.A. Moving ahead: The economic impact of reducing physical inactivity and sedentary behaviour. Ottawa: The Conference Board of Canada, 2014.

[2] Tremblay, M.S. Standardized use of the terms "sedentary" and "sedentary behaviours" [letter]. Appl Physiol Nutr Metab, 37, 540-542, 2012.

[3] Katzmarzyk, P.T., Church, T.S., Craig, C.L., Bouchard, C. Sitting time and mortality from all causes, cardiovascular disease, and cancer. Med Sci Sports Exerc, 51(5), 998-1005, 2009.

[4] Martin, A., Fitzsimons, C., Jepson, R., et al. Interventions with potential to reduce sedentary time in adults: Systematic review and meta-analysis. Br J Sports Med, 49(16), 1056-63, 2015.

[5] Prince, S.A., Saunders, T.J., Gresty, K., Reid, R.D. A comparison of the effectiveness of physical activity and sedentary behaviour interventions in reducing sedentary time in adults: A systematic review and meta-analysis of controlled trials. Obes Rev, 15 (11), 905-19, 2014

[6] Kinman, G., Jones, F. A life beyond work? Job demands, worklife balance, and wellbeing in UK academics. J Hum Behav Soc Environ, 17(1-2), 41-60, 2008.

[7] Fountaine, C.J., Piacentini, M., Liguori, G.A. Occupational sitting and physical activity among university employees. Int J Exerc Sci, 7(4), 295-301, 2014.

[8] Irwin, J.D. Prevalence of university students' sufficient physical activity: A systematic review. Percept Motor Skills, 98, 927-43, 2004.

[9] Peachey, M.M., Richardson, J., Gravesande, J., Dal-Bello Haas, V., Tang, A. Strategies for quitting sitting at home and in the workplace: A systematic review and meta-analysis. British Journal of Sports Medicine, In press. 
[10] Craig, C.L., Marshall, A.L., Slostrom, M. et al. International physical activity questionnaire: 12 -country reliability and validity. Med Sci Sports Exerc, 35(8), 1381-95, 2003.

[11] Orji, R., Vassileva, J., Mandryk, R. Towards an effective health interventions design: An extension of the health belief model. Online J Public Health Inform, 4(3), e9, 2012.

[12] King, K.A., Vidourek, R.A., English, L., Merianos, A.L. Vigorous physical activity among college students: using the health belief model to assess involvement and social support. Arch Exerc Health Dis, 4(2), 267-9, 2014.

[13] Champion, V.L. Instrument development for health belief model constructs. ANS Adv Nurs Sci, 6(3), 73-85, 1984.

[14] Strathman, A., Gleicher, F., Boninger, D.S., Edwards, C.S. The consideration of future consequences: Weighing immediate and distant outcomes of behavior. Journal of Personality and Social Psychology, 66, 742-752, 1994.

[15] Hayes, D., Ross, C.E. Concern with appearance, health beliefs, and eating habits. J Health Soc Behav, 28(2), 120-130, 1987.

[16] Sparks, P., Guthrie, C.A. Self-identity and the Theory of Planned Behavior: A useful addition or an unhelpful artifice? $J$ Appl Soc Psychol, 28(15), 1393-1410, 1998.

[17] Deshpande, S., Basil, M.D., Basil, D.Z. Factors influencing healthy eating habits among college students: An application of the health belief model. Health Marketing Quarterly, 26(2), $145-64,2009$.

[18] Judice, P.B., Hamilton, M.T., Sardinhas, L.B., Silva, A.M. Randomized controlled pilot of an intervention to reduce and break-up overweight/obese adults' overall sitting time. Trials, 16, 490-501, 2015.

[19] Lohr, S. Sampling: design and analysis. Nelson Education, 2009.

[20] Buman, M.P., Winkler, E.A., Kurka, J.M. et al. reallocating time to sleep, sedentary behaviors, or active behaviors: associations with cardiovascular disease risk biomarkers, NHANES 2005-2006. Am J Epidemiol, 179 (3), 323-334, 2014.
[21] Matthews, C.E., Kozey Keadle, S., Troiano, R.P. et al. Accelerometer-measured dose-response for physical activity, sedentary time, and mortality in US adults. Am J Clin Nutr, 104, 1424-32, 2016.

[22] Healy, G.N., Wijndaele, K., Dunstan, D.W. et al. objectively measured sedentary time, physical activity, and metabolic risk: The Australian Diabetes, Obesity and Lifestyle Study (AusDiab). Diabetes Care, 31,369-371, 2008.

[23] Healy, G.N., Dunstan, D.W., Salmon, J. et al. objectively measured light-intensity physical activity is independently associated with 2-h plasma glucose. Diabetes Care, 30, 1384-1389, 2007.

[24] Statistics Canada. 2017. "Canadian health measures survey: Activity monitor data". The Daily. April 2017 Statistics Canada Catalogue no. 11-001-X.

Http://www.statcan.gc.ca/daily-quotidien/170419/dq170419e-eng. pdf. (accessed July 27, 2017).

[25] O’Donoghue, G., Perchoux, C., Mensah, K. et al. A systematic review of correlates of sedentary behaviour in adults aged 18-65 years: A socio-ecological approach. BMC Public Health, 16, 163, 2016.

[26] Prince, S.A., Reed, J.L., McFetridge, C., Tremblay, M.S., Reid, R.D. Correlates of sedentary behaviour in adults: A systematic review. Obes Rev, 18(8), 915-935, 2017.

[27] Adams, J. Consideration of immediate and future consequences, smoking, status, and body mass index. Health Psychol, 31(2), 260-263, 2012.

[28] Gilson, N.D., Burton, N.W., van Uffelen, J.G., Brown, W.J. Occupational sitting time: Employees' perceptions of health risks and intervention strategies. Health Promot J Austr, 22(1), 38-43, 2011.

[29] Westmas, J.L., Gil-Rivas, V., Cohen-Silver, R. Designing and implementing interventions to promote health and prevent illness. In: Friedman, Cohen-Silver, R, editors. Foundations of Health Psychology. Oxford University Press, New York, New York, 2006, $52-70$. 